\title{
Investigation of the blood proteome in response to spinal cord injury in rodent models
}

\author{
Charlotte H. Hulme ${ }^{1,2}$, Heidi R. Fuller ${ }^{1}$, John Riddell ${ }^{3}$, Sally L. Shirran ${ }^{4}$, Catherine H. Botting ${ }^{4}$, Aheed Osman ${ }^{2}$ and Karina T. Wright $^{1,2}{ }^{\bowtie}$ \\ (c) Crown 2021
}

STUDY DESIGN: Explanatory and mechanistic study.

OBJECTIVES: A better understanding of the 'whole-body' response following spinal cord injury (SCI) is needed to guide future research aimed at developing novel therapeutic interventions and identifying prognostic indicators for SCl. This study aimed to characterise the blood proteome following contusion or complete $\mathrm{SCl}$ compared to a sham injury in rat models.

SETTING: United Kingdom.

METHODS: Pooled blood samples from one and seven days after a contusion (serum; $n=5$ ) or from 14 days and 112 days postcomplete transection SCI (plasma; $n=8$ ) and their sham-injured counterparts were subjected to independent iTRAQ nanoflow liquid chromatography tandem mass-spectrometry proteomic analyses. Pathway analyses of the proteins that were differentially abundant between $\mathrm{SCl}$ and their matched sham injured counterparts were completed to indicate biological pathways that may be changed in response to $\mathrm{SCl}$.

RESULTS: Eleven and 42 proteins were differentially abundant ( $\geq \pm 2.0 \mathrm{FC} ; p \leq 0.05)$ between the contusion $\mathrm{SCl}$ and sham injured animals at $24 \mathrm{~h}$ and seven days post-injury, respectively. Seven and tweleve proteins were differentially abundant between complete and sham injured rats at 14 and 112 days post-injury, respectively. Acute-phase response signalling and Liver X Receptor/ Retinoic X Receptor activation were identified as differentially regulated pathways in both models of $\mathrm{SCl}$.

CONCLUSIONS: We have utilised longitudinal preclinical SCI models to provide an insight into the blood proteome changes that result following $\mathrm{SCl}$ and to highlight a number of biological pathways of interest for future studies.

Spinal Cord (2022) 60:320-325; https://doi.org/10.1038/s41393-021-00692-8

\section{INTRODUCTION}

Many clinical and scientific attempts have been made to better diagnose and to develop new treatments to improve the prognosis of individuals following a spinal cord injury (SCI). There is growing evidence that measures of some haematological indices post-injury relate with longer term (12 month) clinical outcome measures in human $\mathrm{SCl}$ patients [1,2]. These studies indicate that over-time the 'whole-body', multi-organ response to $\mathrm{SCl}$ contributes to long-term clinical outcome and that proteins within the blood can be used to assess this phenomenon [1, 2]. Therefore a better understanding of the longitudinal protein changes within the blood following a $\mathrm{SCl}$ is needed to develop novel interventions [3].

The majority of studies that have aimed to understand protein changes that occur following a $\mathrm{SCl}$, have focused upon changes within the SC tissue itself [3]. We have previously reviewed the few studies that have assessed the protein response to $\mathrm{SCl}$ in either the blood or cerebrospinal fluid (CSF) of $\mathrm{SCl}$ animal models or humans with a $\mathrm{SCl}$ [3]. It is particularly desirable to identify markers that can be measured systemically as blood samples can be collected immediately after injury with fewer associated risks compared to CSF samples. Having a better understanding of the proteome response to $\mathrm{SCl}$ in blood, will aid in the development of novel inteventions for $\mathrm{SCl}$, as well as to identify candidate biomarkers that may have the potential to better determine $\mathrm{SCl}$ severity or predict clinical outcome of human with a SCI [4].

Several well-characterised pre-clinical $\mathrm{SCl}$ models exist which aim to represent the different common human $\mathrm{SCl}$ situations, contusive (blunt force) or penetrative (stab) injuries. In animals contusion injuries are commonly modelled using specialised devices that deliver an impact of calibrated force to the surgically exposed spinal cord $[5,6]$. Penetrative injury, in humans more commonly leads to complete $\mathrm{SCl}$, in which a variable cross section of the spinal cord is transected [7]. Surgical exposure and complete incision across all SC tracts is commonly performed in these animal models using either microscissors or a scalpel blade under visual control [8]. Rodent models are invaluable in studying the underlying mechanisms of $\mathrm{SCl}$, as there is evidence that they undergo similar biological processes to humans following injury [9] and allow for comparison to sham injured animals (via surgical exposure of, but no injury to, the SC) whereas such comparator control groups are difficult to identify in the human situation.

Proteomics is a powerful analytical tool that can be used to profile large numbers of proteins in an untargeted manner. We

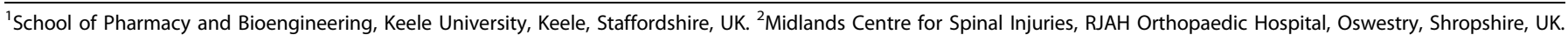

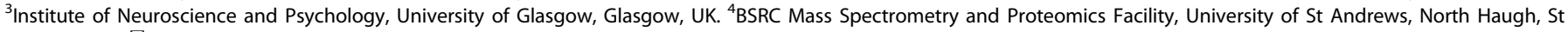
Andrews, UK. ${ }^{\bowtie}$ email: karina.wright1@nhs.net
} 
Table 1. Protein changes in rat blood following contusion spinal cord injury compared to sham injury at either 1 day or 7 days following injury.

\begin{tabular}{|c|c|c|c|c|c|}
\hline & Name & Protein ID & $\begin{array}{l}1 \text { day SCl: } \\
1 \text { day sham }\end{array}$ & $\begin{array}{l}7 \text { days } \mathrm{SCl}: \\
7 \text { day sham }\end{array}$ & $\begin{array}{l}\text { FDR ( } p \text { value) (a) } 1 \text { day SCl: } 1 \text { day } \\
\text { sham; (b) } 7 \text { day SCl: } 7 \text { day sham }\end{array}$ \\
\hline & Haemoglobin subunit alpha-1/2 & HBA-1 & 8.3 & 3.8 & (a) $0.0002 ;$ (b) 0.001 \\
\hline & Angiotensinogen & AGT/SERPINA8 & 2.6 & & 0.02 \\
\hline & $\begin{array}{l}\text { Immunoglobulin kappa light } \\
\text { chain variable region }\end{array}$ & IGKV & & 12.9 & 0.03 \\
\hline & Fibrinogen beta chain precursor & FGB & & 7.9 & 0.02 \\
\hline & Myosin-11 & MYH-11 & & 6.0 & 0.04 \\
\hline & Fibrinogen gamma chain & FGG & & 5.75 & $9.48 \times 10^{-9}$ \\
\hline & Serine protease inhibitor $A 3 M$ & Serpina3m & & 3.4 & 0.001 \\
\hline & Antithrombin-III & SERPINA1 & & 2.6 & 0.0002 \\
\hline & $\begin{array}{l}\text { Gamma-2a immunoglobulin } \\
\text { heavy chain }\end{array}$ & $\operatorname{lgg}-2 a$ & & 2.4 & 0.002 \\
\hline & Attractin & ATRN & & 2.3 & 0.04 \\
\hline & $\begin{array}{l}\text { Immunoglobulin gamma-2b, } \\
\text { partial }\end{array}$ & Igh-1a & & 2.2 & 0.006 \\
\hline \multirow[t]{22}{*}{ Down in $\mathrm{SCl}$} & Antithrombin-III & SERPINC1 & -3.9 & & $2.72 \mathrm{E}-05$ \\
\hline & $\begin{array}{l}\text { Complement component } \\
4 \text {, gene } 2\end{array}$ & $C 4 b$ & -3.5 & & 0.04 \\
\hline & Gelsolin & GSN & -3.4 & & 0.0002 \\
\hline & Complement C5 & $\mathrm{C} 5$ & -3.3 & & 2.07E-08 \\
\hline & C4b-binding protein alpha chain & C4BP1 & & -9.6 & $1.99 \mathrm{E}-05$ \\
\hline & $\begin{array}{l}\text { Inter-alpha-inhibitor } \mathrm{H} 4 \\
\text { heavy chain }\end{array}$ & ITIH4 & & -9.4 & $3.88 \mathrm{E}-05$ \\
\hline & Apolipoprotein E & APOE & & -8.1 & 0.0002 \\
\hline & Alpha-1-antiproteinase & SERPINA1 & & -7.8 & 0.0004 \\
\hline & Complement factor $\mathrm{H}$ & $\mathrm{CFH}$ & & -7.5 & $1.77 \mathrm{E}-11$ \\
\hline & Complement component $\mathrm{C} 6$ & $\mathrm{C} 6$ & & -6.3 & $6.26 \mathrm{E}-06$ \\
\hline & Fibronectin 1 & FN1 & & -5.9 & $1.80 \mathrm{E}-07$ \\
\hline & Major urinary protein & Mup & & -5.8 & 0.002 \\
\hline & Complement $\mathrm{C} 1 \mathrm{~S}$ subcomponent & C1s & & -5.8 & 0.0009 \\
\hline & Plasma protease $\mathrm{C} 1$ inhibitor & SERPING1 & & -5.5 & 0.0008 \\
\hline & Clusterin & $\mathrm{Clu}$ & & -4.9 & 0.009 \\
\hline & Apolipoprotein C-I & APOC1 & & -4.5 & 0.02 \\
\hline & Apolipoprotein B-100 & APOB & & -4.1 & $6.44 \times 10^{-14} 6$ \\
\hline & Fetub protein & FETUB & & -3.5 & 0.001 \\
\hline & Apolipoprotein A-I preproprotein & Apoa1 & & -3.0 & 0.008 \\
\hline & Angiotensinogen & Agt & & -2.7 & 0.027 \\
\hline & Afamin, isoform CRA_c & Afm & & -2.6 & $9.02 \times 10^{-8}$ \\
\hline & Complement C4 & $\mathrm{C} 4$ & & -2.3 & 0.004 \\
\hline
\end{tabular}


Table 1 continued

\begin{tabular}{llccc} 
Name & Protein ID & $\begin{array}{l}\mathbf{1} \text { day SCI: } \\
\mathbf{1} \text { day sham }\end{array}$ & $\begin{array}{l}\mathbf{7} \text { days SCI: } \\
\mathbf{7} \text { day sham }\end{array}$ & $\begin{array}{l}\text { FDR ( } \boldsymbol{p} \text { value) (a) } \mathbf{1} \text { day SCl: } \mathbf{1} \text { day } \\
\text { sham; (b) } \mathbf{7} \text { day SCl: } \mathbf{7} \text { day sham }\end{array}$ \\
\hline Lumican & LUM & & -2.2 & 0.05 \\
Complement component C7 & C7 & & -2.2 & $6.08 \times 10^{-5}$ \\
$\begin{array}{l}\text { Pigment epithelium-derived } \\
\text { factor precursor }\end{array}$ & SERPINF1 & -2.1 & 0.002 \\
Vitamin K-dependent protein S & PROS1 & & -2.0 & 0.002
\end{tabular}

$F D R$ false discovery rate, $\mathrm{SCl}$ spinal cord injury.

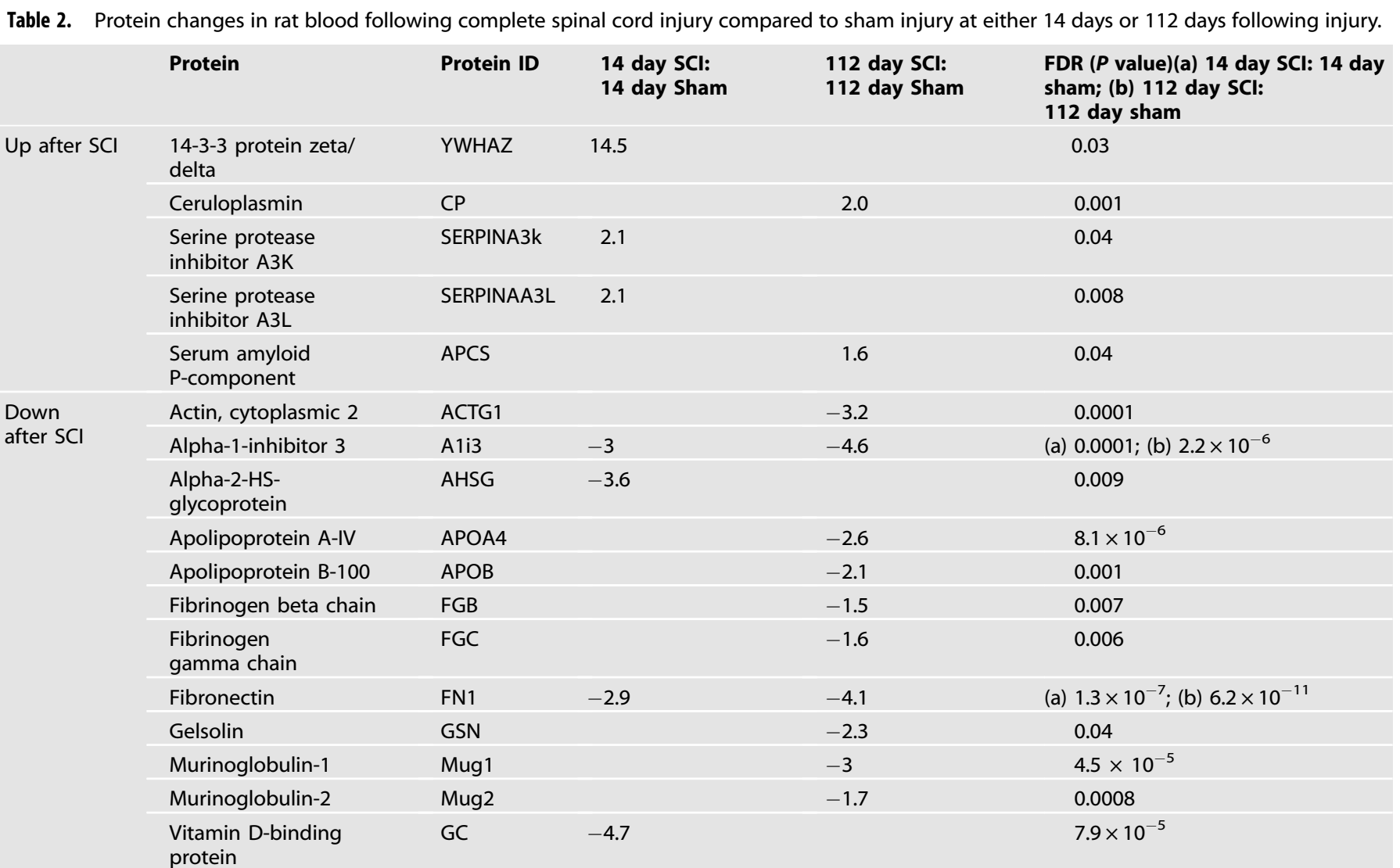

FDR false discovery rate, $\mathrm{SCl}$ spinal cord injury.

have assessed the blood proteome of rat models of both a contusion and a complete transection $\mathrm{SCl}$ to determine whether we can detect differences between SC injured and sham injured rodents. Consideration of the blood proteome in such pre-clinical injury models could provide a more in-depth understanding of the biochemical response to $\mathrm{SCl}$ compared to sham injury and how these responses change over time in each independent model.

\section{METHODS}

\section{Animals used in the study}

All experimental procedures were approved by the Ethical Review Panel of the University of Glasgow and carried out in accordance with the Animals (Scientific Procedures) Act 1986 and adhering to our recommended good practice for $\mathrm{SCl}$ rodent models [10]. Blood samples were collected surplus to the study outcomes and were used in this study to maximise the output from animal experiments in the spirit of the 3R's of animal use (replacement, refinement and reduction) [11]. Blood samples were obtained at 1 day $(n=5)$ or 7 days $(n=5)$ after a contusion injury performed at the C6 level [12] or at 14 days $(n=8)$ or 112 days $(n=8)$ after a complete spinal cord transection performed at the T9 level [13]. Control blood samples were obtained from animals that underwent sham surgery performed at the same spinal level. Further details of the animal experiments are included in the supplementary material (appendix 1).

Isobaric tag for relative and absolute quantitation proteomics Two independent proteomic experiments were performed; one for the contusion $\mathrm{SCl}$ (serum samples) and the other for the complete $\mathrm{SCl}$ (plasma samples) models. Briefly, samples were pooled from the different injury and timepoint groups, then prepared and analysed using isobaric tagging for relative and absolute quantitation (iTRAQ) proteomics, as described previously [14] and detailed in the supplementary material (Appendix 1). Proteins which were differentially abundant between the $\mathrm{SCl}$ and matched sham counterparts were selected where $p<0.05$ and the fold change (FC) was $\geq \pm 2.0$.

\section{Pathway analysis of proteomic datasets}

Proteins were analysed using the pathway enrichment and topological analysis tools in Ingenuity (Qiagen, US) [15] to identify and visualise the canonical pathways which are differentially effected between $\mathrm{SCl}$ and sham 


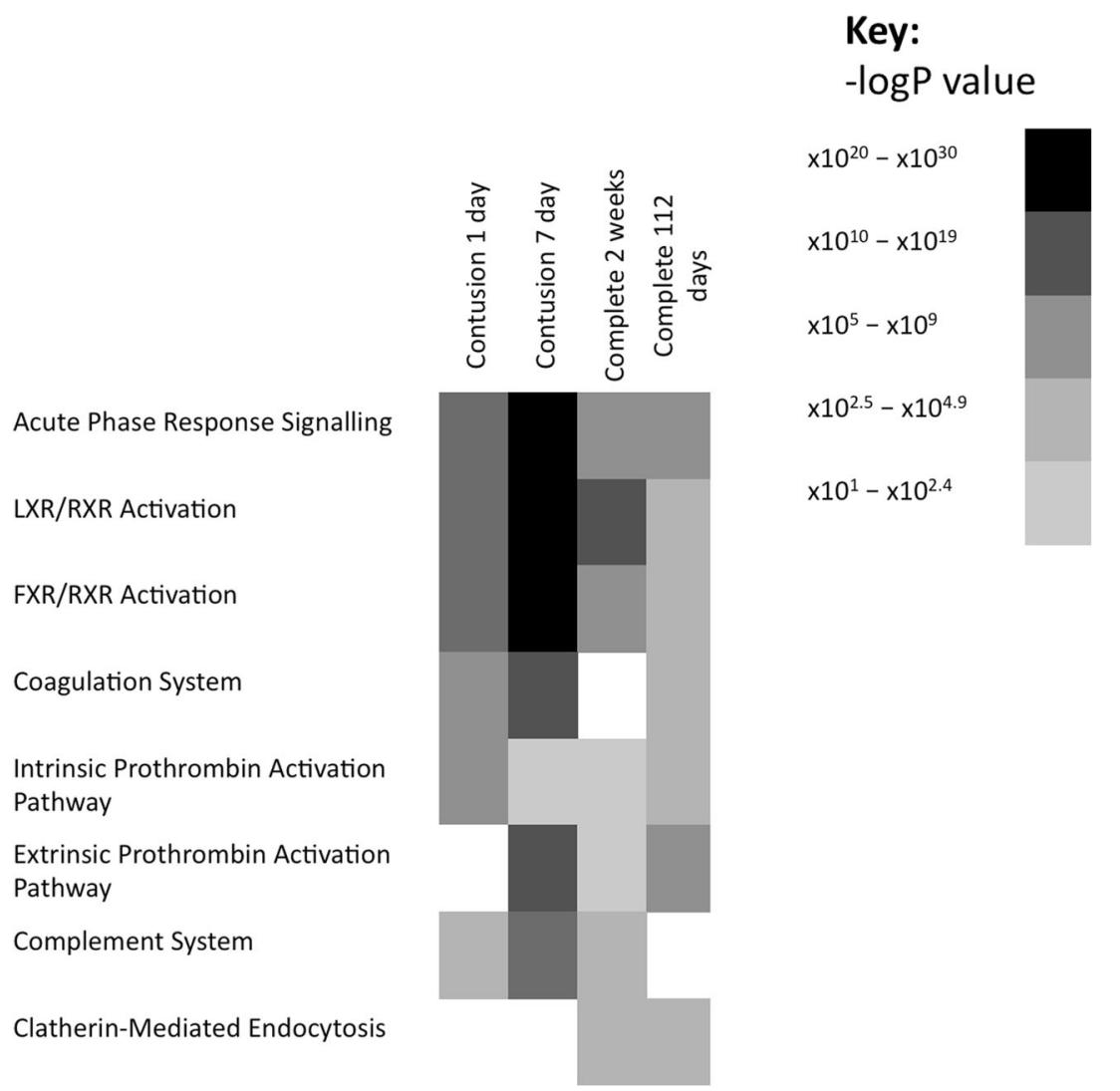

Fig. 1 Heat map demonstrating canonical pathways that were most significantly enriched in spinal cord injured compared to sham injured rats. The significance of the association of a given canonical pathway and the differentially abundant proteins was measured using Fisher's exact test. The heat map demonstrates the strength of the -log $P$ value related to the Fisher's exact test for each pathway in each biological comparator group.

injured rats at each of the timepoints of the study and in the different $\mathrm{SCl}$ models. Functional annotations that were assigned a $p$ value $>0.05$, as assessed using a Fisher's exact test were removed from the list.

\section{RESULTS}

Differential abundance of proteins in the contusion versus sham injured animals

All the proteins identified in the proteomic analysis of serum from contusion $\mathrm{SCl}$ or sham counterparts are included in supplementary proteomic Table 1 . Eleven proteins demonstrated $\geq 2.0$ fold differential abundance in the serum of contusion SC injured compared to sham injured rats at one day post-injury (Table 1). At seven days post-injury 42 proteins were differentially abundant between contusion and sham injured rodents (Table 1). Three of these proteins demonstrated common changes in abundance at both timepoints; Fibrinogen alpha chain isoform 1 and haemoglobin subunit alpha-1/2 had increased and C9 Protein had decreased abundance across time i.e. at one day and seven days post-injury (Table 1). Supplementary proteomic Table 2 and 3 detail all the proteins identified with $\geq 2$ peptides and any ratio between $\mathrm{SCl}$ and sham counterparts at $24 \mathrm{~h}$ and seven days postinjury, respectively.

\section{Differential abundance of proteins in the complete versus sham injured animals}

Supplementary proteomic table 5 details all the identified proteins following iTRAQ proteomic analysis of plasma from the complete $\mathrm{SCl}$ and sham counterpart animals. In serum collected at 14 days post injury, a comparison of complete SC injured compared to sham injured rats identified seven proteins that were differentially abundant $( \pm 2.0 \mathrm{FC})$, three of which increased in abundance after $\mathrm{SCl}$ (Table 2). Twelve serum proteins demonstrated a differential abundance at 112 days after a SCl compared to sham injury, with two proteins showing increased abundance and 10 showing decreased abundance (Table 2). Supplementary proteomic tables 6 and 7 detail all the proteins identified with $\geq 2$ peptides and any ratio between $\mathrm{SCl}$ and sham counterparts at 14 days and 112 days post-injury, respectively.

\section{Biological functions associated with the protein changes identified}

In an aim to better interpret what the protein changes related to in terms of biological function, pathway analysis was performed. Biological pathways which had significant numbers of differentially abundant proteins connected with them (determined by Fisher's exact test) could be identified.

Several functional pathways were associated with the protein changes identified in the plasma of rats with a contusion $\mathrm{SCl}$ compared to sham injured rats in the acute (1 day) phase of injury (Fig. 1). The most significant functional pathways were: acute phase response signalling ( $p=1.1 \times 10^{-13}$; predicted inhibition); liver $\mathrm{X}$ receptor/retinoic $\mathrm{X}$ receptor (LXR/RXR) Activation $(p=1.8 \times$ $\left.10^{-10}\right)$; coagulation system $\left(p=9.6 \times 10^{-9}\right)$ and intrinsic prothrombin activation pathway $\left(p=1.1 \times 10^{-6}\right)$. Several of these pathways were still effected at a more sub-acute phase of injury (7-days post-injury); namely, LXR/RXR activation $\left(p=6.0 \times 10^{-17}\right)$, acute phase response signalling $\left(p=1.6 \times 10^{-13}\right)$ and the coagulation system $\left(p=7.2 \times 10^{-15}\right)$. Other pathways, however, were indicated as altered only at seven days post-injury, such as the extrinsic prothrombin activation pathway $\left(p=5.9 \times 10^{-12}\right)$ (Fig. 1). 
The same analyses were performed based on the protein changes detected within the serum of rodents with a complete SCl. Pathways that were associated with protein changes seen at two weeks postinjury included LXR/RXR activation $\left(p=3.5 \times 10^{-12}\right)$ and acute phaseresponse signalling $\left(p=3.0 \times 10^{-9}\right)$, the complement system $(p=$ $\left.4.1 \times 10^{-4}\right)$ and Clatherin-mediated endocytosis signalling $(p=4.27 \times$ $10^{-4}$ ) (Fig. 1). Clatherin mediated endocytosis was also altered based upon protein changes seen at 112 days following a complete injury $\left(p=1.1 \times 10^{-4}\right)$, along with acute phase response signalling $(p=1.5 \times$ $\left.10^{-8}\right)$, the extrinsic prothrombin activation pathway $\left(p=3.0 \times 10^{-5}\right)$ and the coagulation system $\left(p=1.5 \times 10^{-4}\right)$ (Fig. 1).

These biological pathways may provide targets for future work aimed at targeting and/or developing therapies for $\mathrm{SCl}$ specific responses. Furthermore, these analyses help to convey whether specific biological functions are altered over time.

\section{DISCUSSION}

We have presented one of the first studies to assess how the blood proteome changes after $\mathrm{SCl}$ in both contusive and complete transection SCl models. This investigation has presented a unique opportunity to determine the blood protein response to $\mathrm{SCl}$ in order to greater understand the mechanisms underlying $\mathrm{SCl}$ and repair.

One of the limitations of this study is that blood samples were collected from animals at different timepoints following $\mathrm{SCl}$ and different blood fractions were collected (plasma and serum). Therefore, this study does not aim to directly compare between the two different models but rather to demonstrate that following $\mathrm{SCl}$ there are protein changes within the blood, which can be detected in either blood fraction: serum or plasma. The range of timepoints in these pre-clinical models has allowed for the blood proteome to be assessed longitudinally, from the acute phase ( 1 day post-contusion $\mathrm{SCl}$ ) to the chronic phase (112 day postcomplete $\mathrm{SCl}$ ) of injury. These proteomic analyses highlight that there is a differential response to $\mathrm{SCl}$ compared to sham injury, which can be detected in the blood in these rodent models overtime.

Pathway analyses were used to provide a better understanding of what the proteome changes might relate to in terms of biological response to injury. These analyses allow for the assessment of biological functional changes which present a more global response within the blood. Therefore commonality in functional pathway changes across time, irrespective of the blood fraction and injury severity (contusion or complete) indicates that these functional pathways are likely a specific response to $\mathrm{SCl}$ and not sham injury and can be taken forward for further study with much greater confidence. Moreover when the results from the two rodent models are assessed independently, these novel proteomic datasets present scientists with an understanding of the systemic response to two widely used $\mathrm{SCl}$ models.

In the contusion model, only 11 proteins showed differential abundance, based on our selection criteria, between the injured and the sham injured animals at $24 \mathrm{~h}$ post-injury. This limited number of alterations based on our fold change and $p$ value cutoffs, along with the large number of common proteins identified in both the injured and sham sera, indicates that many of the protein changes that do occur as an immediate response to injury could be common to both $\mathrm{SCl}$ and sham injuries. Of the proteins that were most highly differentially abundant in $\mathrm{SCl}$ compared with sham injury at this acute timepoint, several were associated with the haematological system and haemostasis e.g. fibrinogen alpha chain isoform 1; haemoglobin subunit alpha $1 / 2$; an observation that is strengthened by our pathway analysis, which also associated protein changes in this timeframe with the coagulation system and the intrinsic prothrombin activation pathway. These findings indicate that there is a response to $\mathrm{SCl}$ which can be detected within the blood immediately after injury and highlights the potential of assessing proteins which are not associated with the $\mathrm{SCl}$ itself, e.g. neuronal or glial related protiens, but rather that there may be a 'whole-body', multi-organ response that is different in response to $\mathrm{SCl}$ compared with sham injury. Interestingly, by seven days post-injury high numbers of differentially abundant proteins were seen, many of which displayed large FC differences in abundance, thus indicating that there may be value in measuring blood proteins through the acute phase of injury.

Studying the plasma proteome of rats following a complete injury demonstrated that up to 112 days after injury protein differences can be observed between $\mathrm{SCl}$ and sham injured animals. These proteins can provide an insight into the potential reparative and/or degenerative processes that continue longitudinally post-SCl. As with the contusion model, our pathway analyses have highlighted that changes within the blood occur in response to $\mathrm{SCl}$, such as in the extrinsic prothrombin activation pathway and the coagulation system, and this model highlights that these may go on being implicated for a long period of time following injury. We have previously demonstrated that red blood cell (RBC) measures (RBCs, haematocrit and mean cell haemoglobin) in the blood of humans with $\mathrm{SCl}$ at $7 \pm 4$ days post- $\mathrm{SCl}$ correlate with initial AIS motor and sensory scores [1], confirming that systemic release of red blood cell measures may be indicative of injury severity.

Changes in acute phase response signalling were identified at both the sub-acute (14 day) and chronic (112 day) timepoints following complete injury and the acute ( 1 day) and sub-acute (7 day) timepoints following contusion injury, highlighting that changes in the acute phase response continue longitudinally post$\mathrm{SCl}$. Acute phase response signalling is the first systemic response to trauma [16], therefore it is unsurprising that in the case of $\mathrm{SCl}$, this signalling pathway is activated. This signalling cascade is triggered by inflammatory cytokines which leads to drastically changed protein synthesis by the liver and resultant release of the acute phase proteins [16]. Therefore this signalling pathway provides an attractive target for novel therapies, potentially by targeting upstream inflammatory cytokines using biologic therapies [17]. Changes in this pathway, along with identified changes in LXR/RXR activation, add strength to our previous findings [1] also highlighting the importance of considering the effect of $\mathrm{SCl}$ on other organ systems aside from the nervous system, such as the liver, in contributing to clinical outcome following $\mathrm{SCl}$. In future studies, it would be interesting to assess whether differences in acute-phase response signalling in the different phases of injury exist between individuals with varying injury severities and/or who either do or do not show long-term neurological improvements.

This study presents the first unbiased assessment of the blood proteome in rodent models of $\mathrm{SCl}$. A large number of proteins have been identified which, with further study, may have the potential to inform on the type and severity of injury from the acute through to the chronic phase of $\mathrm{SCl}$. Moreover, we have identified biological mechanisms that are associated with these protein changes, thus providing a better understanding of the blood proteome changes that occur in response to $\mathrm{SCl}$.

\section{DATA AVAILABILITY}

The mass spectrometry proteomics data have been deposited to the ProteomeXchange Consortium via the PRIDE [18] partner repository with the dataset identified PXD021137.

\section{REFERENCES}

1. Brown SJ, Harrington GMB, Hulme $\mathrm{CH}$, Morris R, Bennett A, Tsang WH, et al. A preliminary cohort study assessing routine blood analyte levels and neurological outcome after spinal cord injury. J Neurotrauma. 2019;37:466-80. 
2. Bernardo Harrington GM, Cool P, Hulme C, Osman A, Chowdhury JR, Kumar N, et al. Routinely measured hematological markers can help to predict American Spinal Injury Association impairment scale scores after spinal cord injury. J Neurotrauma. 2020;8:1-8.

3. Hulme CH, Brown SJ, Fuller HR, Riddell J, Osman A, Chowdhury J, et al. The developing landscape of diagnostic and prognostic biomarkers for spinal cord injury in cerebrospinal fluid and blood. Spinal Cord. 2017;33:114-25.

4. El Masri W, Kumar N. Traumatic spinal cord injuries. Lancet. 2011;377:972-4.

5. Koozekanani SH, Vise WM, Hashemi RM, McGhee RB. Possible mechanisms for observed pathophysiological variability in experimental spinal cord injury by the method of Allen. J Neurosurg. 1976;44:429-34.

6. Zhang N, Fang M, Chen H, Gou F, Ding M. Evaluation of spinal cord injury animal models. Neural Regen Res. 2014;9:2008-12.

7. McCaughey EJ, Purcell M, Barnett SC, Allan DB. Spinal cord injury caused by stab wounds: incidence, natural history, and relevance for future research. J Neurotrauma. 2016;33:1416-21. https://doi.org/10.1089/neu.2015.4375. Available from

8. Fouad K, Schnell L, Bunge MB, Schwab ME, Liebscher T, Pearse DD. Combining Schwann cell bridges olfactory-ensheathing glia grafts chondroitinase promotes locomot recovery complet transection. Spinal Cord. 2005;25:1169-78.

9. Cheriyan T, Ryan DJ, Weinreb JH, Cheriyan J, Paul JC, Lafage V, et al. Spinal cord injury models: a review. Spinal Cord. 2014;52:588-95.

10. Lilley E, Andrews MR, Bradbury EJ, Elliott H, Hawkins $P$, Ichiyama RM, et al. Refining rodent models of spinal cord injury. Exp Neurol. 2020;328:113273 https://doi.org/10.1016/j.expneurol.2020.113273. December 2019Available from

11. National Centre for the Replacement Refinement and Reduction of Animals in Research. Research review. 2013. p. 1-5.

12. Hosseinzadeh S, Lindsay SL, Gallagher AG, Wellings DA, Riehle MO, Riddell JS, et al. A novel poly-E-lysine based implant, Proliferate ${ }^{\oplus}$, for promotion of CNS repair following spinal cord injury. Biomater Sci. 2020;8:3611-27.

13. Lu P, Graham L, Wang $Y$, Wu D, Tuszynski M. Promotion of survival and differentiation of neural stem cells with fibrin and growth factor cocktails after severe spinal cord injury. J Vis Exp. 2014;89:1-9.

14. Fuller HR, Slade $R$, Jovanov-Milošević $N$, Babić $M$, Sedmak $G$, Šimić $G$, et al. Stathmin is enriched in the developing corticospinal tract. Mol Cell Neurosci. 2015;69:12-21.

15. Ingenuity Qiagen. Ingenuity Knowledge Base. 2014.

16. Gruys E, Toussaint MJM, Niewold TA, Koopmans SJ. Acute phase reaction and acute phase proteins. J Zhejiang Univ Sci 2005;6:1045-56.

17. Rider P, Carmi Y, Cohen I. Biologics for targeting inflammatory cytokines, clinical uses, and limitations. Int J Cell Biol. 2016;2016 (4).

18. Vizcaino JA, Csordas A, Del-Toro N, Dianes JA, Griss J, Lavidas I, et al.Update of the PRIDE database and related tools. Nucleic Acids Res. 2016;44:D447-56. 2016D1

\section{AUTHOR CONTRIBUTIONS}

$\mathrm{CHH}, \mathrm{HRF}, \mathrm{KTW}$ and JR conceptualised and designed the study. $\mathrm{CHH}, \mathrm{SLS}, \mathrm{CHB}$ and JR collected data which was then analysed and interpreted by CHH, HRF, KTW, SLS, CHB and JR. CHH, HRF, JR, AO, SLS, CHB and KTW drafted the manuscript, critically revised and approved the final article. Funding for the study was obtained by KTW, HRF and AO. All authors read and approved the final manuscript.

\section{FUNDING}

We would like to thank the Institute of Orthopaedics and the Midlands Centre for Spinal Cord Injury (MCSI) for funding this research. This work was also supported by the Wellcome Trust [grant number 094476/Z/10/Z] which funded the purchase of the TripleTOF 5600 mass spectrometer at the BSRC Mass Spectrometry and Proteomics Facility, University of St Andrews.

\section{COMPETING INTERESTS}

The authors declare no competing interests.

\section{STATEMENT OF ETHICS}

We certify that all applicable Institutional and governmental regulations concerning the ethical use of human volunteers/animals were followed during the course of this research.

\section{ADDITIONAL INFORMATION}

Supplementary information The online version contains supplementary material available at https://doi.org/10.1038/s41393-021-00692-8.

Correspondence and requests for materials should be addressed to Karina T. Wright.

Reprints and permission information is available at http://www.nature.com/ reprints

Publisher's note Springer Nature remains neutral with regard to jurisdictional claims in published maps and institutional affiliations.

\begin{abstract}
cc (i) Open Access This article is licensed under a Creative Commons Attribution 4.0 International License, which permits use, sharing adaptation, distribution and reproduction in any medium or format, as long as you give appropriate credit to the original author(s) and the source, provide a link to the Creative Commons license, and indicate if changes were made. The images or other third party material in this article are included in the article's Creative Commons license, unless indicated otherwise in a credit line to the material. If material is not included in the article's Creative Commons license and your intended use is not permitted by statutory regulation or exceeds the permitted use, you will need to obtain permission directly from the copyright holder. To view a copy of this license, visit http://creativecommons. org/licenses/by/4.0/.
\end{abstract}

(c) Crown 2021 